\title{
Agregados, conjuntos e a tese da indeterminação da referência
}

\author{
Araceli Velloso \\ UFG \\ ar.velloso@gmail.com]
}

resumo 0 objetivo desse artigo é lançar luz sobre a tese da indeterminação da referência de Quine, usando para isso a distinção feita por Frege entre agregados e conjuntos. Além da distinção fregiana, usaremos também algumas noções de teoria dos modelos, tais como "modelos alternativos" e "morfismos entre traduções".

palavras-chave Quine; tese da indeterminação da referência; Frege; agregados e conjuntos; morfismo entre traduções

\section{Introdução}

Nos parágrafos 21 a 25 do livro "Os fundamentos da aritmética", Frege discute as várias abordagens tradicionais à noção de "número natural". Sua apresentação crítica visa às concepções chamadas psicologistas dessa noção, aquelas que subscrevem a tese de que o conceito de "número" seria obtido por algum processo de abstração feito por sujeitos empíricos a partir de dados da sensibilidade.

Apesar de ter como objetivo final definir o que é "número" e criticar as definições alternativas, no decorrer de sua discussão, Frege estabelece uma distinção fundamental para nós entre agregados e conjuntos. Seu objetivo ao fazer tal distinção era o de mostrar que a atribuição numérica envolvia uma propriedade de segunda ordem. Nosso objetivo, porém, é outro. Queremos usar essa distinção para explicar a tese da indeterminação da tradução de Quine. Nossa hipótese de trabalho é a de que essa 
distinção, feita pela primeira vez por Frege, seja a mesma que aquela usada por Quine para estabelecer a sua tão controversa tese. Acreditamos também que ao usar a distinção fregiana conseguiremos tornar mais claros os argumentos de Quine. Para alcançar nosso objetivo, seguiremos os passos de Frege até o ponto em que o filósofo consegue traçar com clareza a distinção que nos interessa. Em seguida, usaremos essa distinção para compreender melhor a mencionada tese de Quine.

\section{Agregados e conjuntos}

A estratégia utilizada por Frege para criticar as abordagens psicologistas é bastante intuitiva, o filósofo começa por comparar as predicações envolvendo números, presentes na linguagem ordinária, com aquelas predicações que envolvem propriedades de primeira ordem atribuíveis diretamente a objetos físicos. A primeira etapa dessa comparação consiste em argumentar que as expressões numéricas não são predicáveis diretamente de substantivos concretos e que, portanto, não poderíamos obter o conceito de número por abstração, como fazemos com as propriedades de primeira ordem de um modo geral.

A fim de discutir com seu interlocutor, Frege coloca em seu texto algumas perguntas retóricas como, por exemplo: “'ser verde' e ‘ser 1000' são predicados do mesmo tipo?”, ou "Ao que cada um desses predicados se aplica?". Sua conclusão, no primeiro caso, é que podemos dizer que "a folhagem dessa árvore é verde" ou que "essa folha é verde" e, portanto, "a folhagem dessa árvore" ou "essa folha" são nomes de objetos físicos aos quais o predicado "ser verde" se aplica. No entanto, se pensarmos no segundo caso, o da atribuição de "número", não podemos dizer, ontologicamente falando, que a folha ou a folhagem tenham a propriedade de ser 1000! Dito de outra maneira, as sentenças: "essa árvore tem 1000" " "essa árvore tem 1" são duas sentenças incompletas que logo suscitam as perguntas: "tem 1000 o quê?" e "tem 1 o quê?". A essas perguntas temos de responder: "tem esse número de folhas" ou "tem aquele número de folhagem".

Tendo proposto o argumento de que não podemos atribuir "o nome de um número" a um substantivo qualquer, Frege conclui que não se pode predicar "ser 1000" de um substantivo diretamente. O que fazemos 
efetivamente é usar outro conceito intermediário que viabilize a predicação e complete a sentença, como no exemplo em que predicamos da árvore "ter 1000 folhas". Ou seja, segundo a argumentação de Frege, "1000" não é um termo geral que possamos predicar diretamente de um substantivo como "árvore", pois temos de ter um intermediário que viabilize essa atribuição, o predicado "ter folhas". Á esse predicado, aplicamos um outro predicado: o "1000".

Os argumentos de Frege, no entanto, seguem adiante. O filósofo acrescenta, ao argumento anterior, outro aspecto da predicação que envolve números: a sua arbitrariedade. Assim, se compararmos, ontologicamente, a atribuição de uma cor a um objeto com a atribuição de um número a esse mesmo objeto, mesmo mediada por outro conceito, por exemplo, chegaremos à conclusão de que, em relação à cor, temos de atribuir uma única delas. Não podemos, por exemplo, dizer da mesma árvore, ao mesmo tempo, que a sua folhagem é verde e que a sua folhagem é amarela, mas podemos dizer da mesma árvore que ela "tem 1000 folhas", ou "tem 1 folhagem", ou ainda "tem 1 milhão de moléculas de carbono".

A conclusão desse segundo argumento é a mesma que a do anterior, ou seja, "ser verde" é uma propriedade que se atribui diretamente a objetos físicos, depende de suas características específicas e, por isso, não podemos atribuir mais de um de certo tipo ao mesmo objeto em questão. Ser "1000", no entanto, depende de qual conceito estamos usando para descrever aquilo que está sendo contado. Se estivermos falando de "ser folha de árvore", teremos 1000 folhas, mas se for sobre "ser folhagem" teremos 1 (uma) folhagem. Caso juntemos agora esse aspecto ao anterior, concluiremos finalmente que o elemento intermediário propiciador da atribuição numérica é um conceito de primeira ordem, que possa ser atribuído diretamente a objetos. Vamos chamá-lo daqui em diante de "conceito pivô", pois ele serve como pivô para viabilizar a atribuição numérica. Já o número seria uma atribuição de segunda ordem, pois diria algo, não sobre o objeto diretamente, mas sobre o conceito pivô, no caso do nosso exemplo, sobre as folhas ou sobre a folhagem.

Continuemos acompanhando Frege. O filósofo em seguida distingue outro aspecto da predicação envolvendo números que a distingue da predicação de primeira ordem em geral: a sua universalidade. Ao abstrair- 
mos a cor de um objeto, por exemplo, e formarmos o conceito correspondente àquela cor, só poderemos aplicar com sentido o conceito formado a objetos de certo tipo, objetos que podem ser coloridos. Não faz sentido, por exemplo, dizer que a prova de um teorema é azul. Podemos, contudo, contar qualquer tipo de objeto e, com algum esforço, atribuir com sentido qualquer número ao mesmo corpo físico. Essa terceira observação de Frege se dirige àqueles que defendem serem os números passíveis de serem abstraídos diretamente de objetos físicos.

Com essas três observações em "mãos", Frege em seguida apresenta a sua noção de "agregado". Havíamos comentado que uma predicação envolvendo o nome de um número corresponderia a uma predicação de segunda ordem, mediada por um conceito pivô. Trata-se agora de caracterizar o objeto ao qual se aplica o conceito pivô, o "algo mais".

\section{A noção de "Agregado" e a noção de "conjunto"}

Caso apresente a alguém um maço de cartas e peço: "ache o número disso!" sem especificar o conceito a ser usado, essa pessoa me perguntará: "o que você quer que eu conte: cartas, baralhos, naipes?". Como concluímos anteriormente, tenho de "escolher" um conceito que funcione como "critério" para a minha contagem. Para Frege, não é possível falar de algo que esteja sendo contado independentemente do conceito usado. No entanto, Frege sugere que em muitos casos, mas não todos, dispomos do termo "agregado" para falar de uma parte física do mundo que possui peso, ocupa lugar no espaço, tem limites precisos e pode ser "segmentado", ou separado em partes, de várias maneiras.

"[...] there are very various manners in which an agglomeration

$(\text { Aggregat })^{1}$ can be separated into parts, and we cannot say that one alone would be characteristic.” [grifo meu] (Grundlagen, $\$ 23$, p.30e)

Podemos, por exemplo, considerar certo agregado como 1 milhão de moléculas de elefante. Mas podemos, ao invés de segmentá-lo, tomá-lo inteiro como uma unidade, atribuindo então o número 1, um elefante, por exemplo. Podemos também atribuir o número 0 (zero) e então não teríamos sequer o agregado a ser segmentado ou tomado como um todo! 
Frege usa esse argumento, contra Mill, para concluir que não temos "uma única maneira característica" de segmentar um agregado.

Um dado importante sobre a noção de agregado: para se falar em objetos não é necessário que tenhamos os agregados correspondentes. Assim, se, por um lado, em alguns casos temos o "agregado" e o consideramos como algo que tem peso e limites físicos e que pode ser segregado em "partes" pelos conceitos, dando origem a objetos. Por outro lado, em outros casos, não temos nenhum correlato físico a ser "segmentado". Segundo Frege. podemos, por exemplo, contar objetos abstratos como "provas de um teorema" ou "eventos", mesmo que não haja um agregado a ser segmentado.

Mas, se o agregado é aquilo que vai ser "segmentado", como nos referir ao que é efetivamente contado? O mesmo agregado pode ser composto de 1 milhão de moléculas de elefante ou de 1 elefante. $O$ que são esses "objetos", as moléculas de elefante ou o elefante, por exemplo, que contamos? Segundo Frege, eles são os elementos de um conjunto, ou seja, a extensão do conceito pivô utilizado. Um "objeto" ou elemento pertence a um conjunto da mesma maneira que um membro pode pertencer a um clube sem nunca ter estado nele! Frege dá um exemplo bastante elucidativo a esse respeito. Ele comenta que não precisamos reunir todos os cegos alemães numa sala para poder contá-los, precisamos apenas de um critério para saber quem pertence à lista e quem não pertence. Esse critério é o nosso conceito pivô, no nosso exemplo, ser cego e pertencer ao império alemão. Segundo o critério escolhido, podemos agora falar dos objetos ${ }^{2}$ que pertencem àquele conjunto.

Comparemos agora as duas noções, a de conjunto e a de agregado. Enquanto um elemento (o objeto) pertence a um conjunto sem fazer fisicamente parte dele, mesmo que seja um objeto concreto, como as moléculas de elefante, por exemplo, a parte ou "pedaço" de um agregado está sempre dentro de seus limites físicos, de tal maneira que, ao afastarmos esse "pedaço", a orelha do elefante, teremos outro agregado, mais leve e menor. Consideremos novamente o exemplo do elefante. A pata do elefante é uma parte do elefante (relação de parte e todo) e o elefante é elemento do conjunto dos elefantes (relação de pertença), mas a pata do elefante não é elemento do conjunto dos elefantes, ela é elemento do conjunto das patas de elefantes. Podemos concluir, portanto, que a relação 


\section{4}

de parte e todo pressupõe a idéia de um elemento mínimo primordial universal, enquanto a relação de pertença não. Aliás, muito pelo contrário: a relação de pertença estabelece, com efeito, que qualquer coisa possa ser tratada como objeto, seja ela concreta ou abstrata, sendo elemento de algum conjunto.

A relação de parte e todo é sempre transitiva, mas a relação de pertença nem sempre. Se a orelha do elefante é uma parte da cabeça do elefante e a cabeça do elefante é uma parte do elefante, então a orelha do elefante é uma parte do elefante. Contudo, como observamos no parágrafo anterior, a orelha do elefante pertence ao conjunto das orelhas de elefante e o elefante ao conjunto dos elefantes, sem que um conjunto seja parte do outro. Ou seja, esses dois elementos pertencem a conjuntos diferentes.

Como é sabido, conjuntos também podem ter uma relação de parte e todo entre eles, a relação de estar contido “ $\sqsubset$ ”. Se o conjunto dos elefantes está contido no dos animais mamíferos, então os seus elementos são também elementos do conjunto maior. A diferença é bastante sutil, podemos ter um conjunto, novamente o das patas de elefantes, que contenha como elemento patas de elefante, e que seja ele próprio elemento de outro conjunto, por exemplo, o conjunto dos conjuntos de patas de animais, sem que esse primeiro conjunto esteja contido no último e, portanto, sem que os seus elementos sejam também elementos desse último conjunto, o conjunto de conjuntos de patas de animais.

A conclusão mais importante a qual chegamos é a de que a relação de parte e todo é uma relação bem diferente da de pertença, embora em alguns casos, como o dos objetos concretos, ela possa parecer ser a mesma. Assim, após a distinção feita por Frege concluímos que o mesmo agregado pode ser segregado por diferentes conceitos, produzindo extensões também diferentes. Nos casos em que podemos falar em agregados, as extensões diferentes são também segmentações em partes de tamanhos diferentes. Mas, podemos falar de extensões mesmo onde não encontramos um agregado correspondente.

Um último ponto importante: quando as extensões variam, variam também os conceitos que as determinam. Isso quer dizer que o que varia é um par intensão/extensão. O que fica fixo é o agregado. É claro que nos exemplos de Frege os agregados já se encontram separados em partes, o que gera a confusão inicial, não falamos em partes não destacadas de 
elefante, mas na pata do elefante já separada de seu corpo em nossa imaginação. Como veremos mais adiante, Quine não dá esse passo a mais, o de separar já as partes do elefante (ou, no caso, coelho) do elefante (ou coelho), por razões muito importantes.

Vejamos agora o problema dos conceitos coextensionais, como "criaturas com rins" e "criaturas com coração", por exemplo. Eles também segmentam um mesmo agregado, só que, nesse caso, há uma diferença fundamental: eles produzem os mesmos objetos. Vejamos em mais detalhes essa diferença! Pedro é uma criatura com rins, Pedro também é uma criatura com coração, mas Fernando é um elefante e as inúmeras moléculas anônimas de Fernando são moléculas de elefante. Ou seja, no primeiro caso temos um mesmo conjunto (extensão) e dois conceitos, enquanto no segundo caso temos objetos diferentes e conceitos diferentes. Em ambos os casos, contudo, temos o mesmo agregado.

Um ponto importante merece ser destacado nessa longa explicação. Como vímos, podemos até ter termos gerais coextensionais - duas intensões para a mesma extensão - mas um ponto ressaltado posteriormente por Quine, e que acreditamos ter suas raízes na distinção fregiana, é o de que, se temos duas extensões para o mesmo agregado, temos também de ter duas intensões diferentes, dois conceitos diferentes que o segmentem. Reformulando então a última afirmação do parágrafo anterior: para um mesmo agregado podemos ter extensões $e$, portanto, também intensões diferentes.

\section{Extensões, agregados e a tese da indeterminação da referência}

Vamos agora analisar os argumentos de Quine em favor da indeterminação da referência. Nossa meta é mostrar que os dois filósofos usam fundamentalmente o mesmo argumento: agregados são diferentes de extensões, pois podemos ter, para o mesmo agregado, extensões diferentes. O objetivo de Quine, no entanto, vai numa direção oposta a do de Frege. O filósofo alemão pressupõe uma linguagem universal e pretende mostrar que as predicações envolvendo números não são nem resultado de um processo subjetivo nem de uma observação empírica, mas envolvem uma predicação de segunda ordem que passa pela mediação de um conceito pivô. Já o filósofo americano pretende questionar a possibilidade de se 
falar numa linguagem universal composta de termos, gerais ou singulares. Ou seja, Quine pretende, com a sua tese da indeterminação da tradução, questionar a viabilidade de se falar em pares de intensão-extensão, que estariam associadas previamente aos termos de uma linguagem universal. Ele sugere, alternativamente, tratar todas as palavras como fórmulas vazias que poderiam receber interpretações diferentes, mas que continuariam a descrever o mesmo "mundo". A proposta semântica de Quine, bem distante da de Frege, é a de abandonar a pressuposição de um esquema conceitual único para um único domínio ou modelo e falar em linguagens alternativas. O filósofo, no entanto, estaria também, segundo a nossa leitura, propondo algo comum a toras essas linguagens alternativas: o agregado a ser segmentado, ou talvez a situação estimulativa comum a ambos. Mas vejamos como isso funcionaria em mais detalhes.

O ponto de partida de Quine, como dissemos, é muito diferente do de Frege. Quine imagina uma situação de tradução radical, na qual tivéssemos dois falantes e uma situação estimulativa. $O$ falante 1 dispõe apenas da observação do comportamento global do falante 2, incluindo os proferimentos emitidos por ele, e da sua observação da situação estimulativa comum a ambos. Como recurso disponível para tentar explicitar o que o falante 2 quer dizer, o falante 1 tem apenas a ostensão e a possibilidade de repetir o proferimento e aguardar pelo assentimento ou dissentimento do falante 2. A situação imaginada por Quine é, portanto, uma situação atributiva, na qual precisamos de pelo menos dois falantes. Um ponto importante dessa situação é que temos liberdade para variar a interpretação das expressões sonoras ou escritas do outro falante o quanto quisermos, contanto que elas permaneçam compatíveis com a estimulação comum a ambos.

É nesse contexto, muito diferente do contexto no qual trabalhava Frege, que Quine procura demonstrar a sua tese da indeterminação da referência. Para demonstrar a sua tese, Quine sugere, no seu artigo "Relatividade ontológica”, uma idéia que, no entanto, é bastante próxima da de Frege e da noção de "agregado". A sugestão de Quine é a de que as diferentes possibilidades de tradução de uma palavra, "gavagai" é o exemplo de plantão, sejam diferentes modos de segmentar a mesma "porção dispersa do mundo espaço temporal", sem que uma delas possa ser privilegiada em relação à outra como a maneira correta. 
"If you take the total scattered portion of the spatiotemporal world that is made up of rabbits, and that which is made up of undetached rabbit parts, and that which is made up of rabbit stages, you come out with the same scattered portion of the world each of the three times. The only difference is how you slice it. [ênfase minha]" (QUINE 1969a, 32)

Nesse trecho, Quine se aproxima bastante de Frege ao observar que temos mais de uma maneira de segmentar a mesma "porção dispersa do mundo espaço temporal". Nossa hipótese de trabalho é a de que a noção de "porção dispersa do mundo espaço temporal" esteja desempenhando para Quine a mesma função que a noção de "agregado" desempenhava para Frege. Embora Quine aceite que essa parte do mundo possa ser composta de porções dispersas, assim como Frege, ele também fala na possibilidade de segmentações "slices" diferentes para a mesma "porção dispersa do mundo espaço temporal". Do mesmo modo que Frege, também, Quine considera que a cada diferente segmentação dessa "porção dispersa do mundo espaço temporal" tenhamos conceitos (e, portanto, também extensões) diferentes, aos quais atribuiríamos inclusive números diferentes, como veremos nos exemplos seguintes. Tomemos os exemplos de Quine de possíveis traduções para a sentença de observação "Gavagai!"3:

"Ali coelho!"

"Ali partes não destacadas de coelho!"

"Ali segmento espaço temporal de coelho!"

"Veja, a coelhice novamente!"

Todas as sentenças dos 4 exemplos anteriores podem ser traduções da sentença "Gavagai" para a mesma situação estimulativa presente, ou para o mesmo agregado, ou ainda para a mesma porção dispersa do mundo espaço temporal. Todas as sentenças mencionadas seriam compatíveis com a situação apresentada e, no entanto, cada uma delas parece ter um sentido diferente do da outra. Num caso estamos falando de um individuo e aplicando a ele o termo geral "coelho"; noutro falamos de um agregado ao qual atribuímos o termo geral "partes não destacadas de coelho"; no terceiro, falamos também de um indivíduo ao qual aplicamos o termo geral "segmento espaço temporal de coelho"; e, no último, de um objeto novamente nomeado pelo termo singular "a coelhice presente". 
Para cada uma dessas opções encontramos um termo geral (ou mesmo singular!) diferente, ou seja, temos uma intensão e uma extensão distintas! Para cada um deles, fazemos também atribuições numéricas diferentes. Assim, a propriedade nomeada pelo predicado "ser um coelho" determinaria um conjunto (extensão) contendo 1 elemento. A propriedade nomeada pelo predicado "ser parte não destacada de coelho" determinaria um conjunto (extensão) de 5 elementos. Já o termo singular “a coelhice presente" nomearia um objeto abstrato do qual veríamos apenas uma parte.

"But what is relevant to the preceding reflections is numerical identity.

Two pointings may be pointings to a numerically identical rabbit, to numerically distinct rabbit parts, and to numerically distinct rabbit stages; [...]" (QUINE 1960, 53-54)

"In order to decide among these alternatives we need to be able to ask more than whether a so-and-so is present. We need to be able to ask whether this is the same so-and-so as that, and whether one so-and-so is present or two". [Ênfase minha] (QUINE 1969b, 2)

Essas observações, até o ponto em que foram apresentadas, no entanto, não nos permitem concluir que há uma indeterminação fundamental na referência/extensão de cada termo. Tal tese, caso provada, daria a Quine um forte argumento contra a noção de "sentido" fregiana como uma entidade independente acoplada a cada expressão da linguagem. Seria, portanto, um forte argumento contra a possibilidade de uma linguagem universal, ao menos nos moldes de uma linguagem como a apresentada numa lógica de predicados. Com efeito, dissemos apenas que há mais de uma maneira de se compreender um proferimento isolado, numa situação de tradução radical. Essa falência localizada por si só, contudo, ainda não constituiria uma prova de que temos traduções alternativas incompativeis como o próprio Quine reconhece.

"Given this apparatus, there is no mystery about extension; terms have the same extension when true of the same things". (QUINE 1969a, 35)

Poderíamos simplesmente construir diversas sentenças compatíveis entre si que descrevessem o mesmo agregado de maneiras diferentes. Poderíamos dizer: "Joca é um coelho", ou "Esse agregado é constituído de partes não 
destacadas de coelho", ou "Isso é um segmento espaço temporal de coelho", ou ainda "Eis a coelhice novamente" e com isso poderíamos distinguir o que está sendo dito no interior de uma mesma língua.

O argumento de Quine, contudo, é proposto dentro de um contexto bem diferente do de Frege: o contexto da tradução radical. Nesse caso experimental especial, não pressupomos o significado de uma sentença para, depois, estabelecer suas condições de verdade, mas muito pelo contrário, pressupomos as condições de verdade e, somente então, procuramos encaixar os significados adequados. Mas apenas sentenças têm condições de verdade. E é exatamente essa a proposta de Quine: as alternativas de segmentação são expressas por diferentes traduções para a mesma sentença de observação ${ }^{4}$. Assim, para Quine, a unidade mínima a confrontar o tribunal da experiência em busca de um significado estimulativo é uma sentença e não um termo.

Considerar, a priori, qualquer agregado como segmentável de uma única maneira seria incorreto tanto para Frege quanto para Quine. A diferença é que Quine, ao contrário de Frege, está preocupado em discutir uma teoria do significado e não em estabelecer uma definição de número. Assim, o filósofo americano observa que pressupor uma dessas segmentações como o modo correto de traduzir os termos de uma sentença de observação seria ir muito além da situação de tradução radical, seria, ao nível da linguagem, já optar por uma tradução especifica para os termos gerais envolvidos. Segundo Quine, o primeiro passo para pensar o significado de uma expressão lingüística é considerar uma sentença inteira frente a uma situação de proferimento. A proposta do filósofo americano é não pressupor que, ao segmentarmos essa sentença, já tenhamos os significados, as referências e as extensões dos termos prédeterminadas. Como os proferimentos são compostos como sentenças inteiras e o que as confronta são situações complexas, não podemos começar por uma relação de nomeação ou de denotação já pressuposta. Assim, para que as nossas opções de tradução de "Gavagai!" sentença sejam compatíveis com a situação estimulativa presente, não podemos considerar um agregado já segmentado em partes separadas, mas apenas em partes não destacadas.

"At the level of radical translation, on the other hand, extension itself goes inscrutable". (QUINE 1969a, 35) 
A inversão proposta por Quine é bastante clara: temos apenas sentenças inteiras frente a estimulações presentes. Segundo o filósofo americano, há uma grande diferença entre considerar certa expressão sonora ou escrita como uma palavra e considerá-la como uma sentença inteira de uma só palavra. Quando considerada como um todo, holofrasticamente, como diz ele, a palavra se conecta a situação estimulativa apenas com relação a duas possibilidades: ser o caso ou não ser o caso, ou seja, assentimento ou dissentimento do ouvinte ao proferimento do outro falante.

"'Gavagai' is an observation sentence, firmly translatable

holophrastically as '(Lo, a) rabbit'. But this translation is insufficient to fix the reference of 'gavagai' as a term; that was ... [an] example of the indeterminacy of reference”. (QUINE 1992b, p. 51)

Segundo Quine, nessa situação, podemos sim traduzir uma sentença de observação se a correlacionarmos causalmente com a situação estimulativa. Dizemos que traduzimos um proferimento em bloco como uma expressão que é proferida sempre que temos aquele agregado diante de nós. Isso, contudo, não diz muita coisa sobre o que queremos dizer com nosso proferimento. Não especificamos, por exemplo, sobre o que estamos falando, nem o que estamos afirmando disso. Ou seja, não definimos quais partes do nosso proferimento devem ser consideradas como termos singulares e quais devem ser consideradas como termos gerais, nem quais são esses termos e quais são suas intensões/extensões. Podemos concluir, a partir das teses propostas por Quine, que, numa situação de tradução radical não dispomos ainda das condições de verdade da sentença e, portanto, não dispomos também de uma semântica que nos permita interpretar a nossa linguagem formal ao nível predicativo. Dispomos apenas de várias hipóteses de tradução para a mesma sentença e é por essa razão que o significado dos termos é indeterminado.

Nesse ponto de nossa situação frente a um falante de uma língua desconhecida, não podemos traduzir as palavras resultantes da segmentação dessa mesma sentença de um modo único: temos várias alternativas compatíveis para escolher! Podemos dizer que estamos falando de "Joca" e dizendo dele que é um "coelho"; ou que estamos falando do agregado composto por várias "partes não destacadas de coelho"; ou ainda que estamos nos referindo aquele segmento como um "segmento espaço 
temporal de coelho", i.e., de um objeto extenso no espaço e no tempo resultante de uma coleção de segmentos espaço-temporais; e, mesmo, que estamos falando de um objeto abstrato "a coelhice" e dizendo que ela se encontra instanciada diante de nós. Transformados em sentenças todos esses proferimentos dizem a "mesma coisa" que "Gavagai!" sentença, mas se considerarmos "gavagai" como uma palavra, como um termo que faz parte de uma sentença, essas opções agora podem ser acomodadas nos proferimentos que mencionamos acima.

Um ponto importante é que cada um deles possui o seu termo singular ou geral correspondente, assim se traduzirmos "gavagai" palavra por "partes não destacadas de coelho" não podemos mais traduzir o inicio do proferimento, qualquer que seja ele, por "Joca", temos de traduzir por "essas partes" para obter "Essas partes são partes não destacadas de coelho". Cada uma dessas acomodações é uma interpretação diferente da mesma situação.

Claro, se assumíssemos um desses manuais como sendo o correto, poderíamos então encontrar o significado da sentença completa, fazendo as acomodações necessárias. O ponto importante da tese de Quine é que o manual escolhido não seria o único compatível com a situação estimulativa presente e não teríamos, numa situação de tradução radical, indícios que nos permitissem escolher um em detrimento de outro. Assim, enquanto para Frege podemos chegar ao "resultado" final semântico da frase através da composição do significado de suas partes, para Quine essa composição não é unívoca, pois temos mais de um par intensão/extensão atribuível as partes quando essas são consideradas como partes de um todo sentencial.

\section{0 morfismo dos manuais}

Vejamos agora em detalhes como a acomodação da qual falávamos se daria. Para provar a compatibilidade das diferentes possibilidades de tradução com a mesma situação estimulativa, Quine sugere uma correspondência entre cada palavra do falante 1 e outra do falante 2, as famosas hipóteses analíticas. O conjunto dos termos resultantes dessa correlação é chamado pelo filósofo de "manual de tradução". Essa correspondência, 
no entanto, não seria individualizada, usaríamos operadores que, aplicados as expressões de um manual gerassem expressões do outro, o que garantiria a generalidade e a completude da correspondência. Por exemplo: passaríamos do manual "coelho" para o manual "partes não destacadas de coelho" prefixando expressões com o operador "partes não destacadas de". Aplicar esses operadores equivale a estabelecer uma função que correlacione os dois manuais em questão. Quine chama essas funções de (Proxy function) ou funções substitutivas.

"A Proxy function is any explicit one-to-one transformation, $f$, defined over the objects in our purported universe. By 'explicit' I mean that for any object $x$, specified in an acceptable notation, we can specify $f x$ ". (QUINE 1995, p. 31)

Assim, cada função substitutiva escolhida geraria um "manual alternativo" (ou "modelo alternativo"). O argumento de Quine, portanto, consiste em mostrar que podemos construir vários manuais nos quais a palavra "gavagai" seja traduzida de maneiras diferentes, usando hipóteses analíticas diferentes, mas todos os manuais permaneceriam compatíveis com a estimulação presente graças a reajustes nas traduções, preservando assim a idéia de um núcleo comum traduzível.

A possibilidade de se estabelecer uma função substitutiva que prove um morfismo entre os manuais é de fundamental importância para a tese de Quine, pois estabelece que os vários modelos são efetivamente modelos, ou linguagens alternativas, para aquela situação. Nesse sentido, é importante que Quine ainda possa falar em agregado, como aquela situação estimulativa causadora do proferimento e que permanece como o conteúdo comum aos vários manuais, caso contrário teríamos de nos perguntar se faria sentido dizer que eles são manuais de tradução, afinal eles estariam traduzindo o quê?

Outro ponto importante para o filósofo americano é mostrar que não adianta recorrer a mundos possíveis para fixar a extensão dos termos e, assim, obter as intensões correspondentes, aquilo que Carnap chamava de método extensional (CARNAP 1956), como era o seu projeto inicial juntamente com o filósofo alemão. Dada uma situação de tradução radi$\mathrm{cal}^{5}$, não temos como fixar a extensão, pois ela varia juntamente com a intensão. É isso o que mostra a possibilidade de segmentações diferentes 
do mesmo agregado (porção dispersa do mundo espaço temporal). Essa foi também a nossa conclusão ao acompanhar o percurso dos argumentos de Frege na seção anterior. No trecho seguinte, Quine exprime exatamente essa dificuldade.

"Reference, extension, has been the firm thing; meaning, intension, the infirm. The indeterminacy of translation [of terms] now confronting us, however, cuts across extension and intention alike. The terms 'rabbit', 'undetached rabbit part', and 'rabbit stage' differ not only in meaning; they are true of different things". (QUINE 1969a, p. 35) [ênfase minha]

Para chegar a essa conclusão foi importante para Quine usar exemplos que pudessem ser indistinguíveis numa situação de tradução radical na qual só teríamos disponível a ostensão.

"If you take the total scattered portion of the spatiotemporal world that is made up of rabbits, and that which is made up of undetached rabbit parts, and that which is made up of rabbit stages, you come out with the same scattered portion of the world each of the three times. The only difference is how you slice it. And how to slice it is what ostension or simple conditioning [...] cannot teach". (QUINE 1969a, 32)

Quine não usa exemplo como o baralho de cartas e os naipes, ou mesmo partes destacadas de Coelho. Seus exemplos envolvem sempre termos gerais ou singulares que não possam ser distinguidos através da ostensão. O mais interessante deles foi proposto bem depois da apresentação da sua famosa tese no W\&O. No Stimulus to Science de 1995, Quine propõe como alternativa de tradução para gavagai: "complemento cósmico de coelho". O aspecto interessante desse exemplo está justamente na impossibilidade de se pensar uma ostensão normal, um apontar para uma porção espaço temporal do mundo. Em seu exemplo, Quine recorre, não a ostensão normal, mas a ostensão por deferência, ou seja, o que está sendo usado como referência é todo do universo subtraído da parte apontada. $\mathrm{O}$ exemplo reforça também a tese da indeterminação da referência, pois desvincula a última de um correlato físico. Assim, com a expressão "complemento cósmico de", podemos reinterpretar toda a nossa ontologia fazendo um mapeamento um-para-um de todos os obje- 
tos concretos em seus substitutos (Proxy) e de todos os objetos abstratos em si mesmos. (QUINE 1995, p. 71-72)

\section{Conclusões}

Como dissemos no início do artigo, nosso objetivo principal era o de lançar uma luz sobre a difícil tese da indeterminação da referência de Quine, usando para tanto uma distinção feita inicialmente por Frete entre extensão e agregado. Retomando, portanto, esse nosso objetivo, podemos agora enunciar a tese quiniana seguindo uma sugestão do próprio filósofo americano: a tese consiste em que, no contexto da tradução radical, a referência (ou extensão) de uma palavra ou expressão, considerada como parte de uma sentença, é indeterminada, ou seja, temos mais de uma referência (extensão) possível e não temos como nos decidir a favor de uma delas como a única adequada. Dito ainda em outras palavras, a tese da indeterminação da referência reza que podemos dispor de mais de uma interpretação das palavras que compõem uma sentença para que a sentença como um todo se correlacione corretamente com uma situação estimulativa, sem que haja uma única alternativa de interpretação que seja a única correta. Do ponto de vista atributivo, podemos sempre optar por uma interpretação A e o outro falante por uma, B, sem que haja critérios comportamentais que nos permitam fazer essa distinção.

Outro aspecto muito importante para a compreensão dessa dificil tese é que ela não pode nos levar a conclusão radical de que qualquer conteúdo deverá ser relativo a uma interpretação, sob o risco de que, como acontece com Davidson, acabarmos por não dispormos mais de uma noção de "linguagem". Ou seja, corremos o risco de perdemos a concepção de um processo comunicativo envolvendo algum conteúdo a ser transmitido de falante para falante. É nesse ponto que entram os manuais de tradução. Um dos papeis mais importante desses manuais é mostrar o que pode e o que não pode ser traduzido. Para Quine, podemos ter traduções únicas de sentenças inteiras, as sentenças de observação, quando consideradas holofrasticamente. Podemos também traduzir os termos componentes dessas sentenças, mas sua tradução já não é mais 
determinada, única. Podemos ainda, segundo o filósofo, traduzir os conectivos lógicos, usando uma lógica trivalente.

Mas para poder falar dessa parte positiva da sua tese, Quine tem de distinguir de maneira precisa a correlação entre uma sentença considerada como um proferimento de uma palavra só e a situação estimulativa (caso no qual teríamos uma única opção interpretativa), dos casos nos quais segmentamos a própria sentença em sujeito e predicado, caso no qual ocorrerá indeterminação da referência. Nesse segundo caso ainda falamos em significado de termos e na possibilidade de distinguir termos singulares de gerais, mas só depois de escolhermos o manual a ser usado. A proposta de Quine é a de que segmentações alternativas, usando hipóteses analíticas alternativas, sejam feitas de tal maneira que cada sentença seria verdadeira no seu manual, mas as traduções dos termos seriam incompatíveis.

Para garantir a razoabilidade de se falar ainda em tradução nesse contexto, Quine sugere critérios gerais (ou operadores) que produziriam modelos equivalentes do ponto de vista empírico quando aplicados a todas as expressões: o operador "segmento espaço temporal", o operador "partes não destacadas" ou o operador "complemento".

Vimos também os argumentos de Quine no sentido de que não faz sentido pressupor, nem intensão, nem extensão fixas anteriormente ao estabelecimento da linguagem, ou seja, universais, ou ainda, como o filósofo passa a falar mais tarde, disponíveis a qualquer linguagem. Nesse e nos outros pontos importantes da posição de Quine, pudemos usar alguns argumentos extraídos da obra de Frege, embora devamos ter sempre em mente que para o segundo filósofo eles desempenhavam papéis marcadamente diferentes. No entanto, e isso é verdadeiro principalmente para a distinção entre agregados e extensões, tais argumentos vindos de Frege foram os principais responsáveis pela possibilidade de se falar em semântica e em teorias da linguagem sem a preocupação de discutir a conexão sujeito/mundo, tão problemática para o período moderno da filosofia. Essa distinção, bem como a conclusão de que extensão e intensão variam juntas, são os aspectos mais importantes que pretendíamos destacar nesse artigo como contribuições para a compreensão da relevância da tese da indeterminação da referência de Quine para as teorias da linguagem contemporâneas. 
1 Termo original em alemão.

2 Uma breve nota sobre a noção de "objeto" que está sendo usada por Frege. Para o filósofo alemão, "objeto" é algo indefinível e a caracterização mais precisa que poderíamos dar seria: "Ao admitirmos objetos, sem restrições, como argumentos e valores de funções, surge a questão de o que é isso que chamamos de um objeto. Considero uma definição adequada impossível, uma vez que temos algo por demais simples para admitir análise lógica. É possível apenas indicar o que queremos dizer. Aqui só posso dizer brevemente: um objeto é qualquer coisa que não seja uma função, de tal forma que uma expressão que o designe não contenha nenhum espaço vazio." (FREGE 1977a, 32)

3 Quine faz questão de enfatizar que nesse caso devemos escrever "Gavagai” com maiúscula, para marcar o fato de que se trata de uma sentença. Acrescentamos também o ponto de exclamação para aumentar essa ênfase.

4 A noção de "sentença de observação" sofre várias modificações no decorrer da obra de Quine, contudo, a título de uma definição provisória de trabalho, podemos dizer que uma sentença de observação é uma sentença de ocasião, cujo valor de verdade depende "muito" da situação presente e bem "pouco" das informações prévias que o falante possa vir a ter. Já uma sentença de ocasião é aquela que tem um valor de verdade dependente da situação presente e não de outras informações anteriores. Cf. (VELLOSO 2004, capítulo III, primeira parte).

5 O exemplo envolvendo o Karl (um alemão) dado por Carnap em "Meaning and synomymy in natural languages" não é satisfatório, pois já estaríamos escolhendo uma interpretação específica.

\section{Referências bibliográficas}

CARNAP, Rudolf. 1956. Meaning and Necessity A Study in Semantics and Modal Logic. Chicago:The University of Chicago Press.

FREGE, Gottlob. 1977a. "Function and concept." In: Translations from the philosophical writings of Gottlob Frege, edição: P. GEACH e M. BLACK, 21-41. Oxford: Basil Blackwell 1978. The foundations of arithmetic: a logicomathematical enquiry into the concept of number. Tradução: John AUSTIN. Oxford: Basil Blackwell.

QUINE, Willard V. O. 1995. From Stimulus to Science. Cambridge: Harvard University Press. 
QUINE, Willard V. O. “Ontological Relativity.” In: Ontological Relativity and other essays, por Willard V. O. QUINE, 26-68. New York:

Comlumbia Uiniversity Press, 1969a. 1992b. Pursuit of Truth. Cambridge: Harvard University Press. . 1969b. "Speaking of Objects." In: Ontological Relativity and ohter essays, por Willard V. O. QUINE, 1-25. New York: Comlumbia Uiniversity Press. 1960. Word and Object. Cambridge:The MIT Press.

VELLOSO, A. R. S. 2004. O holismo "moderado" de W.V. O. Quine: um novo verificacionismo "sem dogmas". Rio de Janeiro, Tese (Doutorado em Filosofia): Universidade Federal do Rio de janeiro. 